\title{
Flexible organic ferroelectric films with a large piezoelectric response
}

\author{
Wenxiu Gao ${ }^{1}$, Lei Chang ${ }^{2}$, $\mathrm{He} \mathrm{Ma}^{1}$, Lu You², Jiang Yin ${ }^{3}$, Junming Liu ${ }^{3}$, Zhiguo $\mathrm{Liu}^{3}$, Junling Wang ${ }^{2}$ and \\ Guoliang Yuan ${ }^{1}$
}

Compared with ferroelectric oxides, organic ferroelectric materials are lightweight, flexible and easy to process. They are ideal for applications in the next-generation portable electronics. Here, we demonstrate the room-temperature growth of imidazolium perchlorate $\left(\mathrm{C}_{3} \mathrm{~N}_{2} \mathrm{H}_{5} \mathrm{ClO}_{4}\right)$ ferroelectric films on various substrates, including Pt-coated $\mathrm{Si}$, quartz and, more importantly, on flexible and transparent polyethylene terephthalate (PET). The films have a preferred $(0-1-1)$ or $(10-1)$ orientation. The former shows a piezoelectric response comparable with the response of the $\mathrm{Pb}\left(\mathrm{Zr}_{0.2} \mathrm{Ti}_{0.8}\right) \mathrm{O}_{3} \mathrm{film}$. This is attributed to the smaller elastic constant of the film, which makes it less susceptible to substrate clamping. When grown on PET, the film is transparent and can be bent to radii of a few millimetres without affecting its ferroelectric properties. Our discovery may significantly promote the application of molecular ferroelectrics in flexible and transparent electronics.

NPG Asia Materials (2015) 7, e189; doi:10.1038/am.2015.54; published online 12 June 2015

\section{INTRODUCTION}

Ferroelectric materials possess spontaneous polarizations that usually originate from the collective displacement of ions in the crystals. Applying an electric field leads to polarization reversal that is coupled with a strain response known as the piezoelectric effect. Because of their multifunctionality, ferroelectric materials are widely used in nonvolatile memory, ultrasonic imaging systems and many other devices. ${ }^{1-3}$

Ferroelectricity was originally discovered in Rochelle salts ${ }^{4}$ and later in several other molecular systems. ${ }^{5}$ However, the rapid development of the field took place only after the discovery of ferroelectricity in perovskite oxides, for example, $\mathrm{BaTiO}_{3}$ and $\mathrm{Pb}(\mathrm{Zr}, \mathrm{Ti}) \mathrm{O}_{3} \cdot{ }^{6,7}$ Although these oxide ferroelectrics are more attractive for applications because of their larger polarization and piezoelectric coefficients, they usually contain heavy metals and, therefore, are not environmental friendly. They require a high processing temperature, making them incompatible with current microelectronic systems. They are usually brittle and cannot be used in flexible devices. Organic materials, however, are much more flexible, lightweight, easy to process and are usually transparent. ${ }^{8}$ They are ideal for applications in portable/flexible electronics. During the past several years, molecular ferroelectrics have attained significant advancements, and their properties are now comparable with those of $\mathrm{BaTiO}_{3} \cdot{ }^{9-12}$ For example, the trigonal imidazolium perchlorate $\left(\mathrm{C}_{3} \mathrm{~N}_{2} \mathrm{H}_{5} \mathrm{ClO}_{4}\right)$ crystal has a polarization of $\sim 8 \mu \mathrm{C} \mathrm{cm}^{-2}$ at room temperature, a high $T_{\mathrm{c}}$ of $100^{\circ} \mathrm{C}$ and a low coercive field. ${ }^{12,13}$
Despite recent intensive studies on molecular ferroelectrics, very few reports have addressed the issue of thin film growth, even though it is critical for practical applications. For inorganic ferroelectric materials, high-quality films are usually obtained by their epitaxial growth on lattice matching substrates., ${ }^{2,3}$ However, such substrates are not available for organic molecular ferroelectrics. Furthermore, molecular materials may show growth behaviors that are drastically different from the inorganic ones. ${ }^{14-18}$ Thus, it is important to conduct a systematic investigation of this topic. Here, we report the roomtemperature growth of high quality, flexible and transparent ${ }^{19}$ $\mathrm{C}_{3} \mathrm{~N}_{2} \mathrm{H}_{5} \mathrm{ClO}_{4}$ films on various substrates, including polyethylene terephthalate (PET).

\section{EXPERIMENTAL PROCEDURE}

Pure $\mathrm{C}_{3} \mathrm{~N}_{2} \mathrm{H}_{5} \mathrm{ClO}_{4}$ powders were dissolved in purified water to form a $60 \%$ saturated solution at $25^{\circ} \mathrm{C}$. Pt-coated $\mathrm{Si}(\mathrm{Pt} / \mathrm{Si})$, quartz and indium tin oxide coated PET (ITO/PET) substrates were used for the film growth. A seed layer of $\mathrm{C}_{3} \mathrm{~N}_{2} \mathrm{H}_{5} \mathrm{ClO}_{4}$ was prepared on the substrates by spin coating the solution at 3000 r.p.m., followed by annealing at $120^{\circ} \mathrm{C}$ for $1 \mathrm{~h}$. The substrates were kept in the saturated solution for $0.5,1$ and 3 days, while the water evaporated at $\sim 0.2 \%$ per day at $\sim 25^{\circ} \mathrm{C}$. After growth, the films were dried at $120^{\circ} \mathrm{C}$ for $1 \mathrm{~h}$ before further measurements. For comparison, the $\mathrm{Pb}\left(\mathrm{Zr}_{0.2} \mathrm{Ti}_{0.8}\right) \mathrm{O}_{3}$ and $\mathrm{BaTiO}_{3}$ films were grown on a $\left(\begin{array}{lll}0 & 0 & 1\end{array}\right) \mathrm{SrTiO}_{3}$ substrate with a $50-\mathrm{nm} \mathrm{SrRuO}_{3}$ buffer layer by using pulsed laser deposition at 680 and $710^{\circ} \mathrm{C}$, respectively. The oxygen partial pressure during the growth was $13 \mathrm{~Pa}$, and the laser energy was $150 \mathrm{~mJ}$ per pulse.

${ }^{1}$ School of Materials Science and Engineering, Nanjing University of Science and Technology, Nanjing, PR China; ${ }^{2}$ School of Materials Science and Engineering, Nanyang Technological University, Singapore, Singapore and ${ }^{3}$ National Laboratory of Solid State Microstructures, Nanjing University, Nanjing, PR China Correspondence: Professor J Wang, School of Materials Science and Engineering, Nanyang Technological University, Singapore 639798, Singapore. E-mail: jlwang@ntu.edu.sg or Professor G Yuan, School of Materials Science and Engineering, Nanjing University of Science and Technology, 200 Xiaolingwei, Nanjing 210094, PR China. E-mail: yuanguoliang@njust.edu.cn 

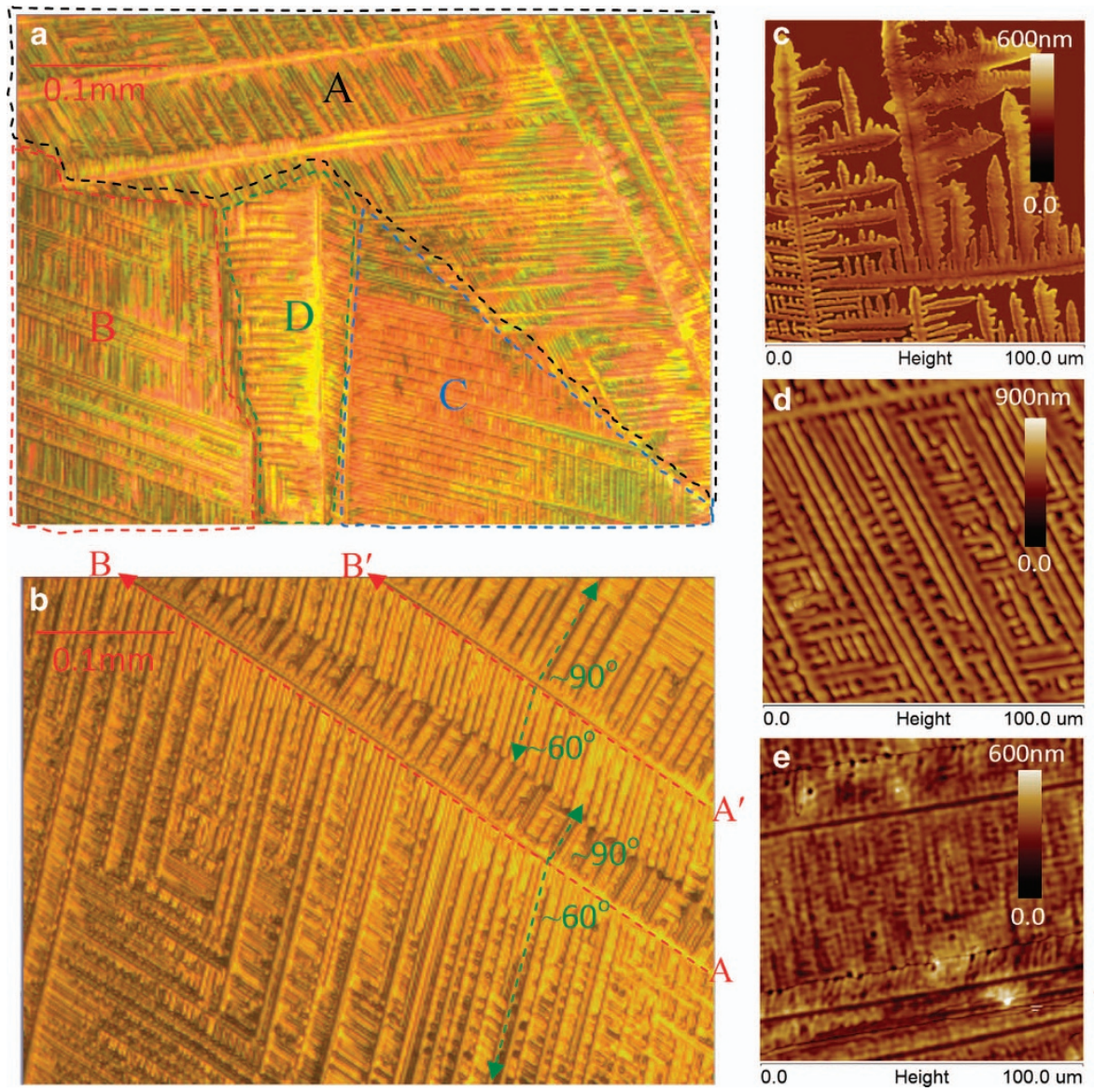

Figure 1 Crystal growth of $\mathrm{C}_{3} \mathrm{~N}_{2} \mathrm{H}_{5} \mathrm{ClO}_{4}$ film on ITO/polyethylene terephthalate. The optical images of $\mathrm{C}_{3} \mathrm{~N}_{2} \mathrm{H}_{5} \mathrm{ClO}_{4}$ films grown from multiple nuclei (a) and a single nucleus (b), respectively. The surface morphology of a film after (c) $12 \mathrm{~h}$, (d) 1 day and (e) 3 days in the same saturated solution at $25 \pm 0.1{ }^{\circ} \mathrm{C}$.

The crystal structure of the films was characterized using an X-ray diffractometer (Brucker D8 Advance, Karlsruhe, Germany). Transmittance spectra were measured by using a UV-visible spectrometer (Shimadzu, Kyoto, Japan). The morphology and the piezoelectric force microscopy (PFM) studies were conducted on an atomic force microscope (Brucker Multimode 8, Camarillo, CA, USA). A $2-\mathrm{V}$ AC voltage at $41 \mathrm{kHz}$ was applied to the $\mathrm{Co} / \mathrm{Cr}-$ coated conductive tip (Bruker MESP-RC) to obtain the domain images. The frequency and the DC bias-dependent piezoelectric responses were measured with a $1-\mathrm{V}$ AC voltage and a conductive tip. The $100-\mu \mathrm{m}$ diameter Pt electrodes were deposited on the films, and the polarization was measured by using a commercial ferroelectric tester (Radiant Multiferroic, Albuquerque, NM, USA). The dielectric responses were measured using a precision impedance analyzer (Agilent 4294A, Santa Clara, CA, USA). The Young's modulus was measured by using a nanoindenter (Agilent G200).

\section{RESULTS AND DISCUSSION}

\section{Film growth and structural analysis}

When the substrates are soaked in the saturated solution and as the water gradually evaporates, the $\mathrm{C}_{3} \mathrm{~N}_{2} \mathrm{H}_{5} \mathrm{ClO}_{4}$ dendritic crystals appear and grow uniformly on each substrate. As an example, the film on the PET is shown in Figure 1a. Several dendritic crystals grow independently in regions $\mathrm{A}, \mathrm{B}, \mathrm{C}$ and $\mathrm{D}$, and the length of the crystals in region A is over $0.5 \mathrm{~mm}$. Dendritic crystal growth has been previously reported for oxides, polymers and molecular materials on amorphous substrates. ${ }^{14-18,20}$ To obtain a large area high-quality film, it is preferred that one nucleus dominates the growth. Various parameters, such as temperature, solubility and the substrate-film interaction, affect the dendritic crystal growth. ${ }^{14-18}$ In general, the crystal growth in a liquid environment is controlled by three processes: (1) the diffusion of molecules through the liquid phase to the growth front; (2) the reorganization of molecules into the film; and (3) the heat dissipation at the growth front. ${ }^{18}$ In our experiments, molecular diffusion should not be the limiting factor because of the highly concentrated solution. Because of the extremely low growth rate, heat diffusion is also unlikely to be an issue. Thus, we suggest that molecular reorganization at the growth front is the controlling process in this case. By slowly evaporating water to control the degree of over saturation, we can prolong the time interval between the appearances of multiple nuclei. As a result, we demonstrate millimeter-scale dendritic film growth from a single nucleus on the ITO/PET (Figure 1b), quartz and Pt/Si substrates (Supplementary Figure $\mathrm{S} 1$ ). Note that $\mathrm{AB}$ and $\mathrm{A}^{\prime} \mathrm{B}^{\prime}$ are two branches originating from the same stem, which can be regarded as the stem for other dendritic crystals.

The well-ordered dendritic crystal branches can merge into a seamless film as water continues to slowly evaporate. There are two prominent growth patterns: one with an $\sim 60^{\circ}$ angle between the stem and the branches and the other with an approximately $90^{\circ}$ angle. These patterns appear because of the fast-growth orientations that depend on the crystal structure and growth conditions. ${ }^{14-18}$ In Figures $1 \mathrm{c}-\mathrm{e}$, we show films that were grown in the same solution with water evaporating at $\sim 0.2 \%$ per day for $12 \mathrm{~h}, 1$ and 3 days, respectively. The dendritic crystals grow on the substrate similar to a vine climbing on a wall during its early stage of growth (Figure 1c). After 1 day, the dendritic crystals are $\sim 3 \mu \mathrm{m}$ wide and $500 \mathrm{~nm}$ thick (Figure 1d). After 3 days, they merge completely into a continuous film, although there 
a

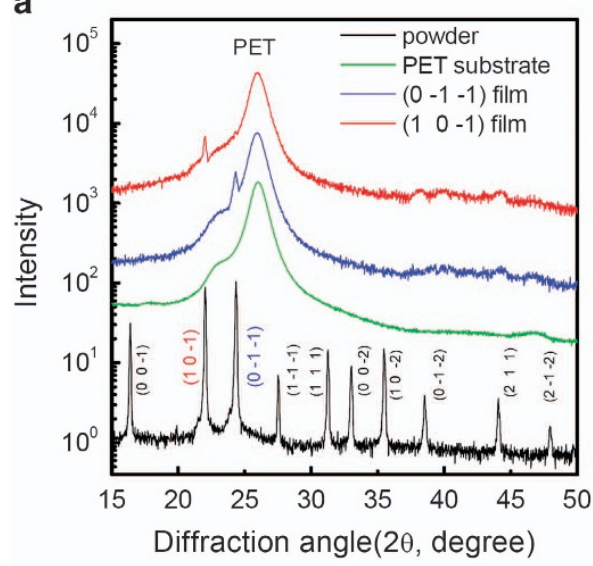

b

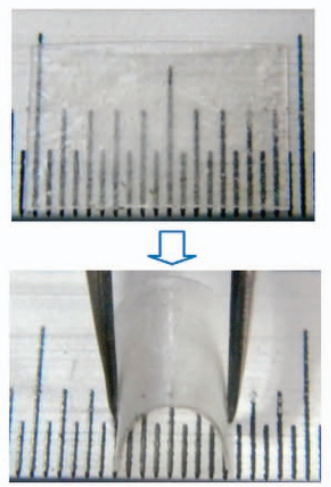

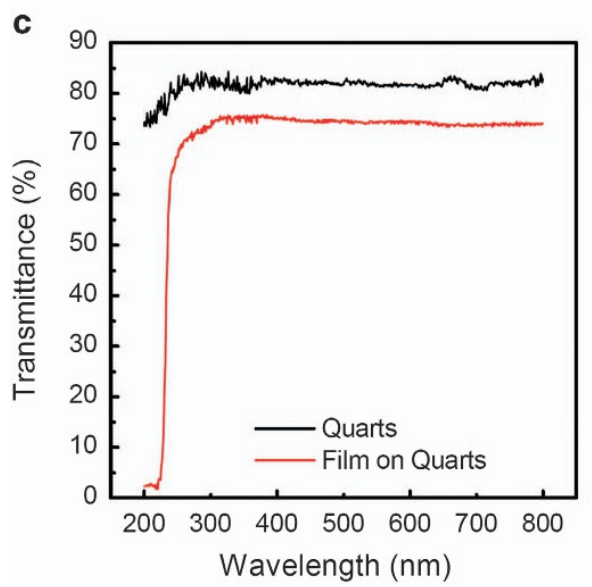

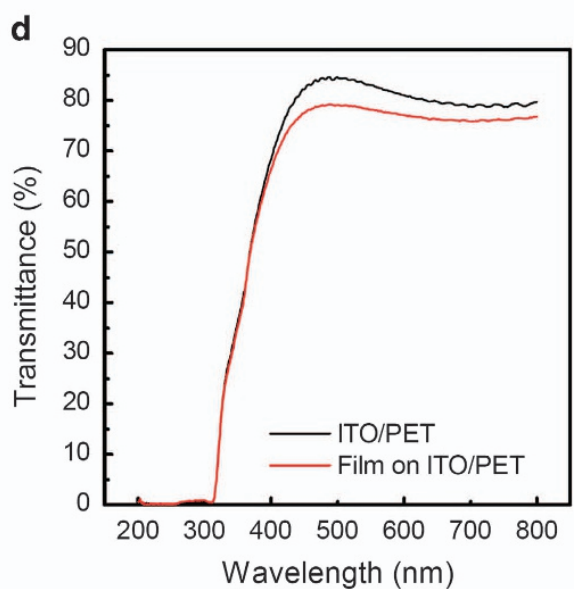

Figure 2 Structure and optical property. (a) X-ray diffraction patterns of $\mathrm{C}_{3} \mathrm{~N}_{2} \mathrm{H}_{5} \mathrm{ClO}_{4}$ powder, $(\mathrm{O}-1-1)$ film and $(1 \mathrm{O}-1)$ film on ITO/polyethylene terephthalate. (b) Optical images demonstrating the flexibility of the films. Transmittances of $\mathrm{C}_{3} \mathrm{~N}_{2} \mathrm{H}_{5} \mathrm{ClO}_{4}$ films on quartz (c) and ITO/polyethylene terephthalate (d) substrates, showing outstanding transparency of the films.
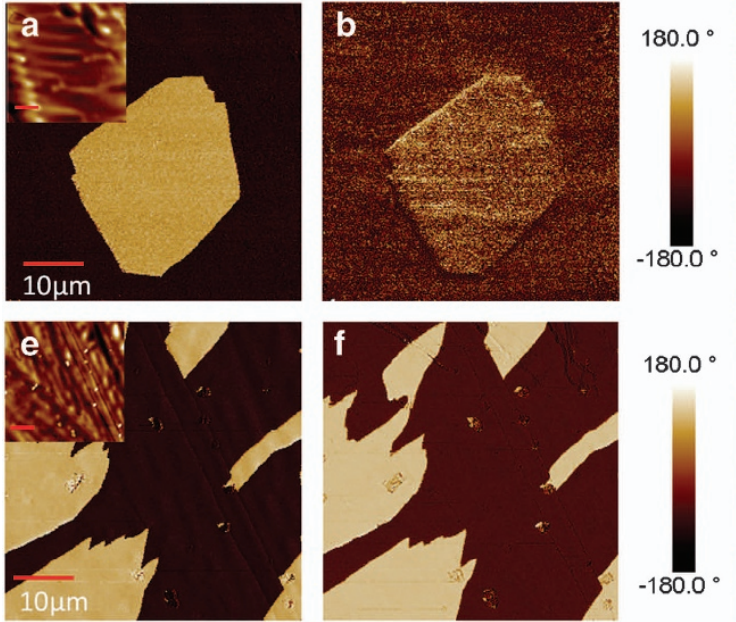
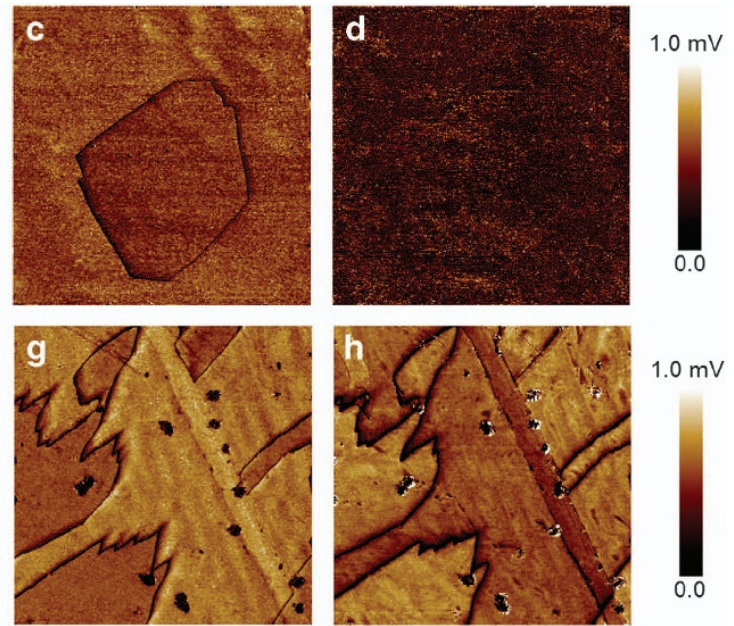

Figure 3 Ferroelectric domain structures of the $\mathrm{C}_{3} \mathrm{~N}_{2} \mathrm{H}_{5} \mathrm{ClO}_{4}$ film. (a) Vertical and (b) lateral piezoelectric force microscopy phase images and (c) vertical and (d) lateral amplitude images of the $(0-1-1)$ film, and (e-h) those of the $(10-1)$ film, where the insets in (a, e) show the corresponding surface morphologies.

are still some traces of dendritic crystals (Figure 1e). Generally, a strong interaction between the film and the substrate is favorable for smooth film growth. ${ }^{16,17}$ This method may be used to grow films of other molecular ferroelectrics from saturated solutions.
Figure 2a shows the X-ray diffraction patterns of the $\mathrm{C}_{3} \mathrm{~N}_{2} \mathrm{H}_{5} \mathrm{ClO}_{4}$ powder, the ITO/PET substrate and the two $1 \times 3-\mathrm{mm}^{2}$ films on the ITO/PET substrate. The $\mathrm{C}_{3} \mathrm{~N}_{2} \mathrm{H}_{5} \mathrm{ClO}_{4}$ ferroelectric phase belongs to the rhombohedral $\mathrm{R} 3 \mathrm{~m}$ point group, the same as that of $\mathrm{LiNbO}_{3}$ 

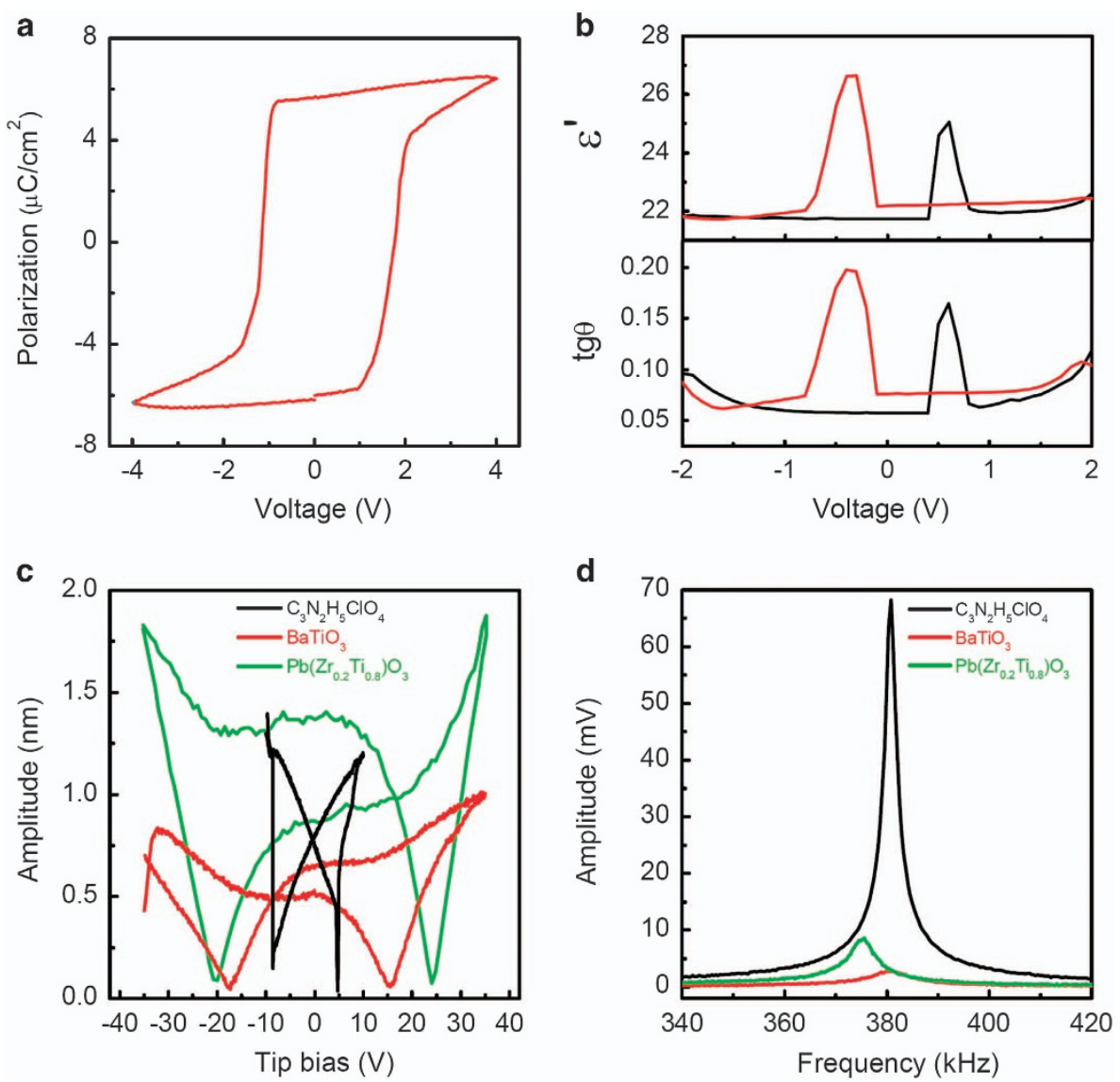

Figure 4 Ferroelectric and piezoelectric properties of the $(0-1-1) \mathrm{C}_{3} \mathrm{~N}_{2} \mathrm{H}_{5} \mathrm{ClO}_{4}$ film on ITO/polyethylene terephthalate. (a) Polarization versus voltage loops measured at $100 \mathrm{~Hz}$. (b) DC field dependence of relative dielectric constant $\left(\varepsilon^{\prime}\right)$ and its loss $(\tan \theta)$. (c) Piezoelectric response versus DC voltage and (d) piezoelectric response versus $\mathrm{AC}$ frequency curves for the $\mathrm{C}_{3} \mathrm{~N}_{2} \mathrm{H}_{5} \mathrm{ClO}$ film, $\left(\begin{array}{lll}0 & 0 & 1\end{array}\right) \mathrm{Pb}\left(\mathrm{Zr}_{0.2} \mathrm{Ti}_{0.8}\right) \mathrm{O}_{3}$ and $\mathrm{BaTiO}_{3}$ epitaxial films, respectively.

(Supplementary Figure S2). In addition to the peaks from the ITO/PET substrate, the first film has only one diffraction peak at $\sim 22^{\circ}$ that arises from the $(10-1)$ planes. Similarly, the second film has a single diffraction peak at $\sim 24^{\circ}$ that arises from the $(0-1-1)$ planes. The $(10-1)$ and $(0-1-1)$ planes are determined by the fastgrowth orientations, which are very sensitive to the growth conditions and the crystal structure. ${ }^{14-18}$ Similar results have been achieved on $\mathrm{Pt} / \mathrm{Si}$ (Supplementary Figure S3) and quarts substrates; thus, the film growth does not depend on the crystal structure of the substrate.

\section{Optical and electrical properties}

After clarifying the film growth process, we then studied the properties of the films. First, by growing the $\mathrm{C}_{3} \mathrm{~N}_{2} \mathrm{H}_{5} \mathrm{ClO}_{4}$ films on ITO/PET and quartz, we demonstrated that it is flexible and transparent in the visible range (Figure $2 \mathrm{~b}$ ). The transmittance of the film on quartz is nearly zero at a wavelength $(\lambda)$ of $230 \mathrm{~nm}$, which increases abruptly to $>70 \%$ at $\lambda=240 \mathrm{~nm}$ (Figure $2 \mathrm{c}$ ). This suggests that the $\mathrm{C}_{3} \mathrm{~N}_{2} \mathrm{H}_{5} \mathrm{ClO}_{4}$ film has a band gap of $\sim 5.4 \mathrm{eV}$. Although the ITO/PET substrate absorbs most light with $\lambda<320 \mathrm{~nm}$, the flexible $\mathrm{C}_{3} \mathrm{~N}_{2} \mathrm{H}_{5} \mathrm{ClO}_{4} / \mathrm{ITO} /$ PET sample shows a high transmittance of $>70 \%$ at $\lambda=390-800 \mathrm{~nm}$, exhibiting excellent transparency in the visible region (Figure 2d). ${ }^{19}$

The ferroelectric properties of the films on the ITO/PET are characterized using both PFM and a conventional ferroelectric tester. $^{11,15}$ Although most of the film is in a single domain state, domain structures are still observed in various regions. In a $50 \times 50-\mu \mathrm{m}^{2}$ area of the $(0-1-1)$ region, yellow/black domains that indicate upward/downward polarization are observed in the vertical PFM phase image (Figure 3a), and the contrast is barely visible in the lateral phase image (Figure $3 \mathrm{~b}$ ). The corresponding vertical and lateral PFM amplitude images are shown in Figures $3 \mathrm{c}$ and $\mathrm{d}$. The near zero signal in Figure $3 \mathrm{~d}$ is consistent with the polarization being perpendicular to the surface. Additionally, the $(0-1-1) \mathrm{C}_{3} \mathrm{~N}_{2} \mathrm{H}_{5} \mathrm{ClO}_{4}$ region usually shows hexagonal domains, which is common in $\mathrm{LiNbO}_{3}$ with a $\mathrm{R} 3 \mathrm{~m}$ point group when the unique polar axis is perpendicular to the surface. $^{21,22}$ However, in a $50 \times 50-\mu \mathrm{m}^{2}$ area of the $(10-1)$ region, domains are clear in both the vertical (Figures $3 \mathrm{e}$ and g) and lateral (Figures $3 \mathrm{f}$ and $\mathrm{h}$ ) PFM images, which is consistent with the fact that there is an angle of $\sim 60^{\circ}$ between the $(10-1)$ and $(0-1-1)$ planes. Similar domain patterns are also observed in films grown on $\mathrm{Pt} / \mathrm{Si}$ substrates (Supplementary Figure S4). Furthermore, the temperaturedependent study reveals that the ferroelectric domains are stable up to $80^{\circ} \mathrm{C}$ (Supplementary Figure S5). However, they change at $90^{\circ} \mathrm{C}$ and disappear at $102{ }^{\circ} \mathrm{C}$ because of the ferroelectric-to-paraelectric phase transition at $\sim 100^{\circ} \mathrm{C} .^{13,20}$ This suggests that $\mathrm{C}_{3} \mathrm{~N}_{2} \mathrm{H}_{5} \mathrm{ClO}_{4}$ films can be used safely below $80^{\circ} \mathrm{C}$.

Typical well-saturated polarization-electric field loops are observed for the $(0-1-1)$ film with the $100-\mu \mathrm{m}$ diameter Pt electrodes (Figure 4a). The saturation polarization is $\sim 6.4 \mu \mathrm{C}-\mathrm{cm}^{-2}$ at $100 \mathrm{~Hz}$, similar to that of the single crystal. ${ }^{13}$ The coercive voltage $\left(V_{\mathrm{C}}\right)$ is lower than $1.7 \mathrm{~V}$ for the $\sim 2 \mu \mathrm{m}$ thick film (that is, $<8.5 \mathrm{kV} \mathrm{cm}^{-1}$ ), which is much smaller than that of perovskite ferroelectrics. ${ }^{2,3}$ This makes it an ideal candidate for applications in low-energy consumption portable 

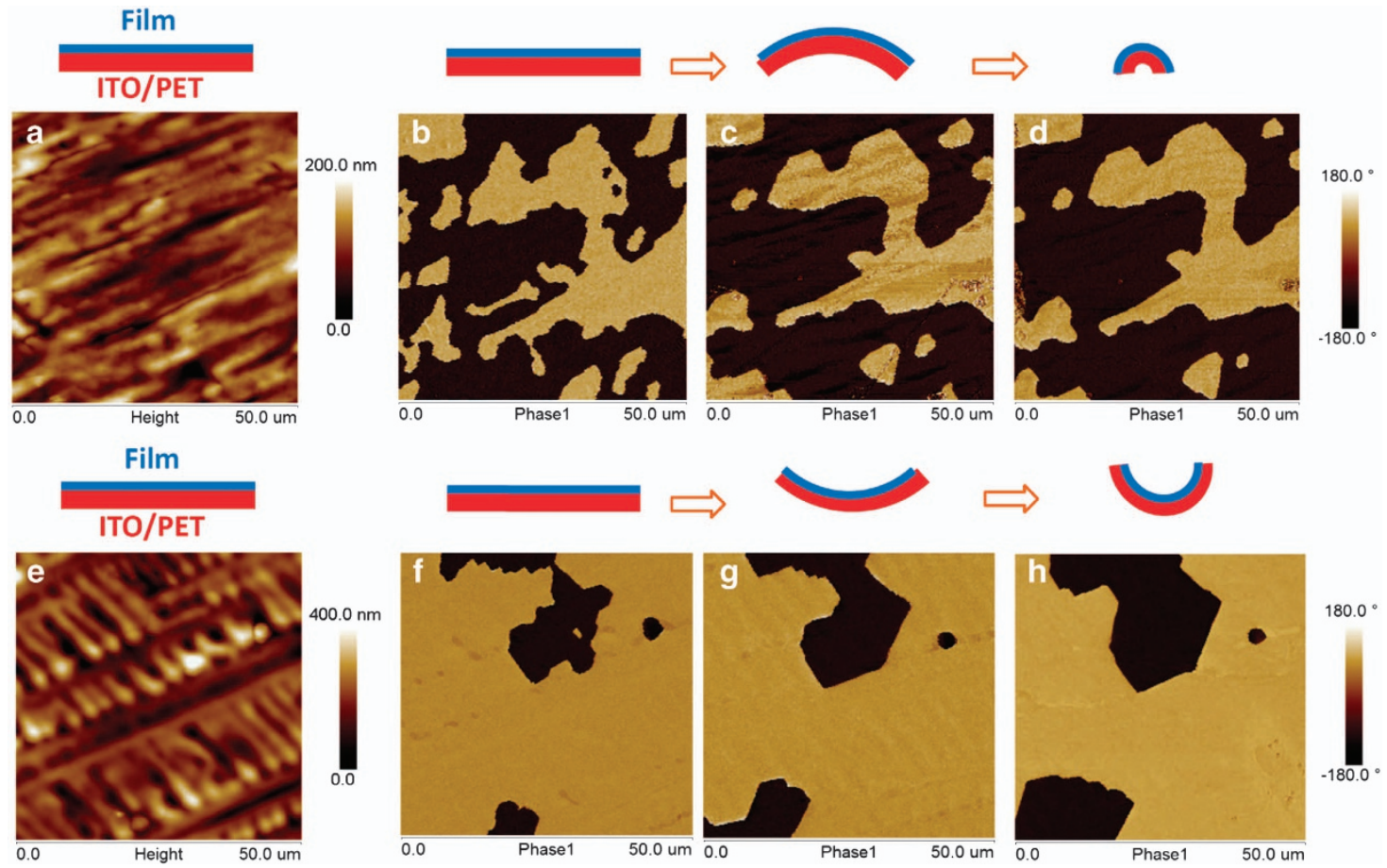

Figure 5 Domain evolution of the bent $(0-1-1) \mathrm{C}_{3} \mathrm{~N}_{2} \mathrm{H}_{5} \mathrm{ClO}_{4}$ on ITO/polyethylene terephthalate. The original surfaces and vertical piezoelectric force microscopy images of the first (a, b) and second (e, f) films, vertical piezoelectric force microscopy images of the first positively bent film with a radius of $7.9 \mathrm{~mm}$ (c) and $3.1 \mathrm{~mm}(\mathbf{d})$, and those of the second negatively bent film with a radius of $6.6 \mathrm{~mm}(\mathbf{g})$ and $4.5 \mathrm{~mm}(\mathbf{h})$.

electronics. The relative dielectric constant and loss show maximum values $\left(\varepsilon^{\prime} \sim 25\right.$ and $\left.\tan \theta \sim 0.2\right)$ near $V_{\mathrm{C}}$ (Figure $4 \mathrm{~b}$ ).

To quantify the piezoelectric response of the $\left(\begin{array}{lll}0 & -1 & -1\end{array}\right)$ $\mathrm{C}_{3} \mathrm{~N}_{2} \mathrm{H}_{5} \mathrm{ClO}_{4}$ film and compare it with the perovskite ferroelectrics, we record the PFM amplitudes of the $(0-1-1) \mathrm{C}_{3} \mathrm{~N}_{2} \mathrm{H}_{5} \mathrm{ClO}_{4}$ film, the $\left(\begin{array}{lll}0 & 0 & 1\end{array}\right) \mathrm{Pb}\left(\mathrm{Zr}_{0.2} \mathrm{Ti}_{0.8}\right) \mathrm{O}_{3}$ and the $\mathrm{BaTiO}_{3}$ epitaxial films using a voltage of $1 \mathrm{~V}$ AC. Figure $4 \mathrm{c}$ shows the DC bias-dependent PFM amplitude, and Figure $4 \mathrm{~d}$ displays the frequency dependence. The typical butterfly shape curves are observed, and the PFM amplitude of the $\mathrm{C}_{3} \mathrm{~N}_{2} \mathrm{H}_{5} \mathrm{ClO}_{4}$ film is comparable with that of $\mathrm{Pb}\left(\mathrm{Zr}_{0.2} \mathrm{Ti}_{0.8}\right) \mathrm{O}_{3}$ and $\mathrm{BaTiO}_{3}$; however, the driving voltage is much smaller. Furthermore, the near resonance piezoelectric response of the $\left(\begin{array}{lll}0 & -1 & -1\end{array}\right)$ $\mathrm{C}_{3} \mathrm{~N}_{2} \mathrm{H}_{5} \mathrm{ClO}_{4}$ film is much larger than that of the $\mathrm{Pb}\left(\mathrm{Zr}_{0.2} \mathrm{Ti}_{0.8}\right) \mathrm{O}_{3}$ and the $\mathrm{BaTiO}_{3}$ epitaxial films (Figure 4d), even though the piezoelectric $d_{33}$ coefficient of the $\mathrm{C}_{3} \mathrm{~N}_{2} \mathrm{H}_{5} \mathrm{ClO}_{4}$ single crystal $\left(\sim 40 \mathrm{pCN}^{-1}\right)$ is much smaller than that of the $\mathrm{Pb}\left(\mathrm{Zr}_{0.2} \mathrm{Ti}_{0.8}\right) \mathrm{O}_{3}$ $\left(>400 \mathrm{pCN}^{-1}\right)$ or the $\mathrm{BaTiO}_{3}$ bulk $\left(>150 \mathrm{pC} / \mathrm{N}^{-1}\right){ }^{20,23,24}$ This is likely because of the smaller elastic constant of $\mathrm{C}_{3} \mathrm{~N}_{2} \mathrm{H}_{5} \mathrm{ClO}_{4}$, which makes the film less susceptible to substrate restriction (note that the Young's modulus of $\mathrm{C}_{3} \mathrm{~N}_{2} \mathrm{H}_{5} \mathrm{ClO}_{4}(\sim 0.8 \mathrm{GPa})$ is much smaller than that of $\mathrm{Pb}\left(\mathrm{Zr}_{0.2} \mathrm{Ti}_{0.8}\right) \mathrm{O}_{3}$ or $\mathrm{BaTiO}_{3}$ (>70 GPa). Furthermore, the near resonance piezoelectric response of the $\mathrm{C}_{3} \mathrm{~N}_{2} \mathrm{H}_{5} \mathrm{ClO}_{4}$ film is at least eight times greater than that of the flexible polyvinylidene fluoridetrifluoroethylene copolymer (PVDF-TrFE) film. ${ }^{20}$ This behavior offers tremendous advantages for applications in portable electronics in which piezoelectric films are more desirable than bulk crystals.

\section{Flexibility of the $\mathrm{C}_{3} \mathrm{~N}_{2} \mathrm{H}_{5} \mathrm{ClO}_{4}$ film}

To demonstrate the flexibility of the film, ${ }^{19}$ we investigate the ferroelectric domain structure of the $\mathrm{C}_{3} \mathrm{~N}_{2} \mathrm{H}_{5} \mathrm{ClO}_{4}$ on the ITO/PET under both tensile and compressive strains using PFM by bending the sample positively and negatively, respectively. Compared with the original domains (Figures $5 \mathrm{a}$ and $\mathrm{b}$ ), no significant changes are observed in the domain structure as the bending radius decreases to $7.9 \mathrm{~mm}$ (Figure 5c) and $3.1 \mathrm{~mm}$ (Figure 5d). Furthermore, in another sample (Figures $5 \mathrm{e}$ and $\mathrm{f}$ ) that is negatively bent to introduce compressive strain, no obvious changes are observed as the bending radius decreases to $6.6 \mathrm{~mm}$ (Figure $5 \mathrm{~g}$ ) and $4.5 \mathrm{~mm}$ (Figure $5 \mathrm{~h}$ ). The piezoelectric responses of both positively and negatively bent films do not weaken according to the amplitude images of those bent samples measured at $41 \mathrm{kHz}$ (Supplementary Figure S6). Therefore, the $\mathrm{C}_{3} \mathrm{~N}_{2} \mathrm{H}_{5} \mathrm{ClO}_{4}$ film can be applied in flexible devices requiring a high piezoelectric response.

\section{CONCLUSIONS}

$\mathrm{C}_{3} \mathrm{~N}_{2} \mathrm{H}_{5} \mathrm{ClO}_{4}$ films with a preferred $(0-1-1)$ or $(10-1)$ orientation were grown on various substrates, including transparent and flexible ITO/PET, at room temperature. The growth starts with dendritic crystals that eventually merge together to form a continuous film. Because of the smaller elastic constant of $\mathrm{C}_{3} \mathrm{~N}_{2} \mathrm{H}_{5} \mathrm{ClO}_{4}$ compared with inorganic ferroelectric materials, the piezoelectric response of the bulk is preserved in the films. The films are also transparent and flexible. The superior properties, the low temperature required for growth and the minimal requirements on the substrates make organic ferroelectric films ideal candidates for applications in next-generation flexible electronics.

\section{CONFLICT OF INTEREST}

The authors declare no conflict of interest.

\section{ACKNOWLEDGEMENTS}

This work is supported by the National Natural Science Foundation of China (11134004 and 11234005), the National Key Project for Basic Research of China (2012CB619406) and a Project Funded by the Priority Academic Program Development of Jiangsu Higher Education Institutions. LC, LY and 
JW acknowledge support from National Research Foundation of Singapore under project NRF-CRP5-2009-04. We also thank Prof. Ren-Gen Xiong from Southeast University, Nanjing, China for providing the $\mathrm{C}_{3} \mathrm{~N}_{2} \mathrm{H}_{5} \mathrm{ClO}_{4}$ powder. Author contributions: WG and LC carried out the thin film growth and electrical measurements; HM conducted the structure and optical measurements; GY and JW designed the experiments, analyzed the data and wrote the manuscript with assistance from LY, JY, JL and ZL.

1 Araugo, C. A., Cuchiaro, J. D., McMillan, L. D., Scott, M. C. \& Scott, J. F. Fatigue-free ferroelectric capacitors with platinum electrodes. Nature $\mathbf{3 7 4}$, 627-629 (1995)

2 Wang, J., Neaton, J. B., Zheng, H., Nagarajan, V., Ogale, S. B., Liu, B., Viehland, D., Vaithyanathan, V., Schlom, D. G., Waghmare, U. V., Spaldin, N. A., Rabe, K. M., Wuttig, M. \& Ramesh, R. Epitaxial BiFeO3 multiferroic thin film heterostructures. Science 299, 1719-1722 (2003).

3 Garcia, V., Fusil, S., Bouzehouane, K., Enouz-Vedrenne, S., Mathur, N. D., Barthelemy, A. \& Bibes, M. Giant tunnel electroresistance for non-destructive readout of ferroelectric states. Nature 460, 81-84 (2009).

4 Valasek, J. Piezo-electric and allied phenomena in rochelle salt. Phys. Rev. 17, 475-481 (1921).

5 Lurio, A. \& Stern, E. Dielectric behavior of single crystals of tri-glycine sulfate (TGS) from 1 kc to 2500 Mc. J. Appl. Phys. 31, 1125-1126 (1960).

6 Forrester, W. F. \& Hinde, R. M. Crystal structure of barium titanate. Nature 156 177-177 (1945)

7 Jaffe, B., Roth, R. S. \& Marzullo, S. Piezoelectric properties of lead zirconate-lead titanate solid-solution ceramics. J. Appl. Phys. 25, 809-810 (1954).

8 Horiuchi, S. \& Tokura, Y. Organic ferroelectrics. Nat. Mater. 7, 357-366 (2008).

9 Horiuchi, S., Tokunaga, Y., Giovannetti, G., Picozzi, S., Itoh, H., Shimano, R., Kumai, R. \& Tokura, Y. Above-room-temperature ferroelectricity in a singlecomponent molecular crystal. Nature 463, 789-792 (2010)

10 Tayi, A. S., Shveyd, A. K., Sue, A. C. H., Szarko, J. M., Rolczynski, B. S., Cao, D., Kennedy, T. J., Sarjeant, A. A., Stern, C. L., Paxton, W. F., Wu, W., Dey, S. K. Fahrenbach, A. C., Guest, J. R., Mohseni, H., Chen, L. X., Wang, K. L., Stoddart, J. F. \& Stupp, S. I. Room-temperature ferroelectricity in supramolecular networks of charge-transfer complexes. Nature 488, 485-489 (2012).

11 Fu, D. W., Cai, H. L., Liu, Y. M., Ye, Q., Zhang, W., Zhang, Y., Chen, X. Y., Giovannetti, G., Capone, M., Li, J. Y. \& Xiong, R. G. Diisopropylammonium bromide is a high-temperature molecular ferroelectric crystal. Science 339, 425-428 (2013).

12 Li, M. Y., Wondergem, H. J., Spijkman, M. J., Asadi, K., Katsouras, I., Blom, P. W. M. \& de Leeuw, D. M Revisiting the $\delta$-phase of poly (vinylidene fluoride) for solutionprocessed ferroelectric thin films. Nat. Mater. 12, 433-438 (2013).
13 Przesławski, J. \& Czapla, Z. Calorimetric studies of phase transitions in imidazolium perchlorate crystal. J. Phys. Condens. Matter 18, 5517-5524 (2006).

14 Zhang, G. L., Cao, Y., Jin, L. X., Zheng, P., Van Horn, R. M., Lotz, B., Cheng, S. Z. D. \& Wang, W. Crystal growth pattern changes in low molecular weight poly (ethylene oxide) ultrathin films. Polymer 52, 1133-1140 (2011).

15 Yang, J. P., Liao, Q., Zhou, J. J., Jiang, X., Wang, X. H., Zhang, Y., Jiang, S. D., Yan, S. K. \& Li, L. What determines the lamellar orientation on substrates? Macromolecules 44, 3511-3516 (2011).

16 Ben-Jacob, E. \& Garik, P. The formation of patterns in non-equilibrium growth. Nature 343, 523-530 (1990)

17 Gránásy, L., Pusztai, T., Börzsönyi, T., Warren, J. A. \& Douglas, J. F. A general mechanism of polycrystalline growth. Nat. Mater. 3, 645-650 (2004).

18 Haxhimali, T., Karma, A., Gonzales, F. \& Rappaz, M. Orientation selection in dendritic evolution. Nat. Mater. 5, 660-664 (2006).

19 Kim, R. H., Kim, H. J., Bae, I., Hwang, S. K., Velusamy, D. B., Cho, S. M., Takaishi, K., Muto, T., Hashizume, D., Uchiyama, M., Andre, P., Mathevet, F., Heinrich, B., Aoyama, T., Kim, D. E., Lee, H., Ribierre, J. C. \& Park, C. Non-volatile organic memory with sub-millimetre bending radius. Nat. Commun. 5, 3583 (2014).

20 Zhang, Y., Liu, Y., Ye, H. Y., Fu, D. W., Gao, W. X., Ma, H., Liu, Z. G., Liu, Y. Y., Zhang, W., Li, J. Y., Yuan, G. L. \& Xiong, R. G. A molecular ferroelectric thin film of imidazolium perchlorate that shows superior electromechanical coupling. Angew. Chem. Int. Ed. Engl. 53, 5064-5068 (2014).

21 Shur, V. Y., Chezganov, D. S., Nebogatikov, M. S., Baturin, I. S. \& Neradovskiy, M. M. Formation of dendrite domain structures in stoichiometric lithium niobate at elevated temperatures. J. Appl. Phys. 112, 104113 (2012).

22 Liu, X. Y., Kitamura, K., Liu, Y. M., Ohuchi, F. S. \& Li, J. Y. Thermal-induced domain wall motion of tip-inverted micro/nanodomains in near-stoichiometric LiNbO3 crystals. J. Appl. Phys. 110, 052009 (2011).

23 Park, S. E. \& Shrout, T. R. Ultrahigh strain and piezoelectric behavior in relaxor based ferroelectric single crystals. J. Appl. Phys. 82, 1804-1811 (1997).

$24 \mathrm{Du}$, X. H., Zheng, J. H., Belegundu, U. \& Uchino, K. Crystal orientation dependence of piezoelectric properties of lead zirconate titanate near the morphotropic phase boundary. Appl. Phys. Lett. 72, 2421-2423 (1998).

(i) This work is licensed under a Creative Commons Attribution 4.0 International License. The images or other third party material in this article are included in the article's Creative Commons license, unless indicated otherwise in the credit line; if the material is not included under the Creative Commons license, users will need to obtain permission from the license holder to reproduce the material. To view a copy of this license, visit http:// creativecommons.org/licenses/by/4.0/

Supplementary Information accompanies the paper on the NPG Asia Materials website (http://www.nature.com/am) 